\title{
A dynamical study of pulse-coupled oscillators in the brain
}

Tanushree Luke ${ }^{1 *}$, Ernest Barreto ${ }^{1,2}$, Paul So ${ }^{1,2}$

From Twenty First Annual Computational Neuroscience Meeting: CNS*2012

Decatur, GA, USA. 21-26 July 2012

In 1967, Winfree [1] proposed a novel mathematical approach to describe phenomena of collective synchrony in nature (i.e. flashing of fireflies, clapping in a theatre, alpha rhythms, etc.) using a large coupled network of phase oscillators with a diversity of natural frequencies. By analyzing this large heterogeneous network from a "mean field" approach, the spontaneous synchrony can be understood as a critical phase transition similar to most statistical mechanical systems.

In this work, we employ this approach to model the phase transitions and bifurcation structures of a large network of pulse-coupled theta neurons [2] by appropri-

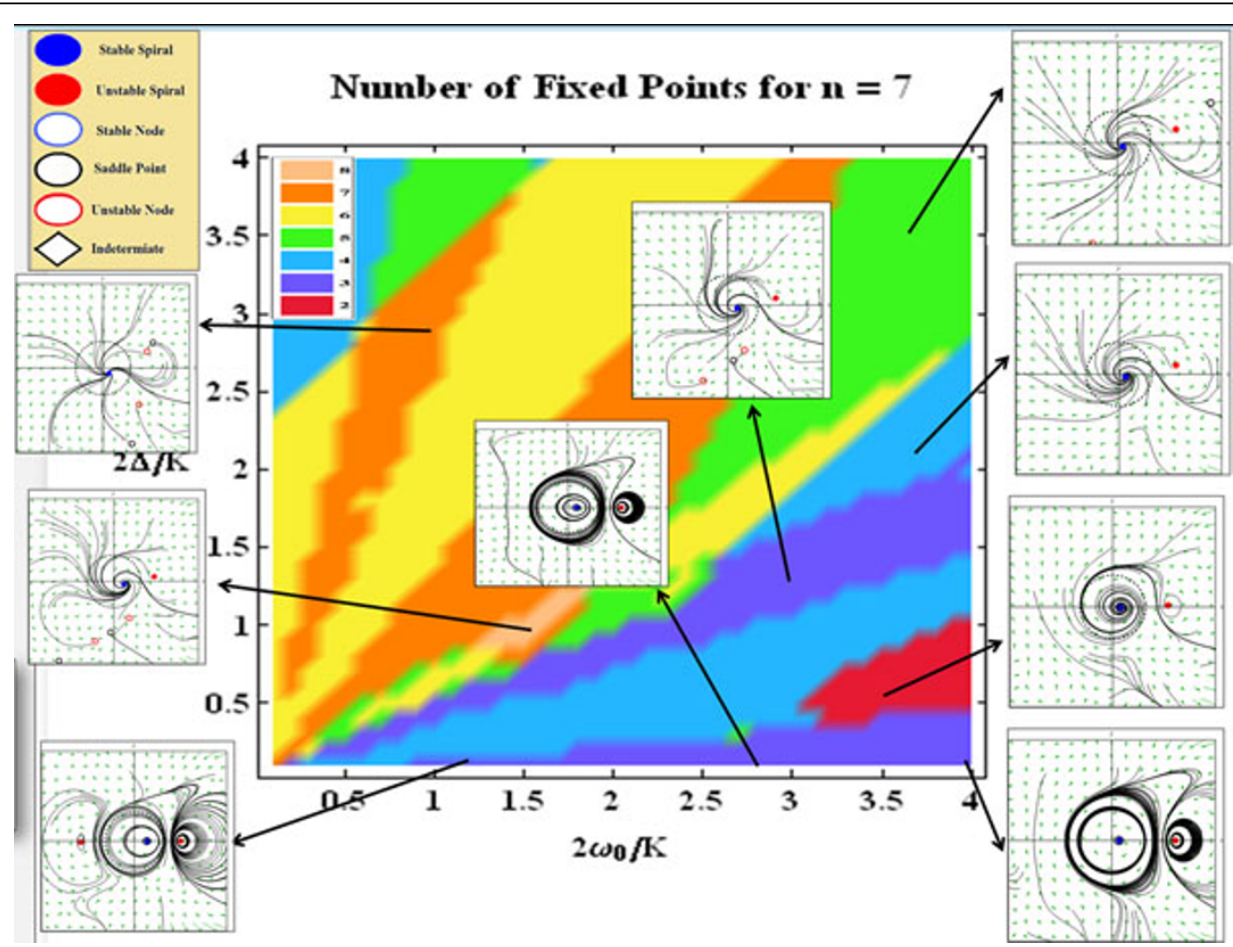

Figure 1 A sample bifurcation diagram showing the complex structure of fixed points at various locations in parameter space, for a sharpness parameter of $(n=7)$. Several representative phase portraits from several distinct region of parameter space are included.

\footnotetext{
* Correspondence: tluke@gmu.edu

'School of Physics, Astronomy,\& Computational Sciences, George Mason University, Fairfax, VA 22030, USA

Full list of author information is available at the end of the article
} 
ate choice of Winfree's "response" and "influence" functions, the latter of which is parameterized by a "sharpness" parameter $n[1]$. As this parameter increases, the influence function approximates the behavior of a pulsecoupled synapse. Assuming a Lorentzian distribution of natural frequencies of width $\Delta$ and mean value $\omega_{0}$, taking the thermodynamic limit, and employing the OttAntonsen reduction method [3], the collective dynamics of the pulse-coupled network can be analytically reduced to a single low-dimensional dynamical equation for the mean field parameter $z(t)$.

We analyze the bifurcation diagrams for different values of the sharpness parameter $n$. We find that more complex behavior is apparent with increasing sharpness of the influence function, and that equilibria outside the physically relevant region (within the unit circle) affect the transient dynamics of $z(t)$ inside the circle. Further, we find that some level of coherence always exists in the network for non-zero coupling, in contrast to other mean field coupled phase oscillator networks $[1,4]$. Most interestingly, heterogeneity is observed to suppress complexity in the collective/macroscopic behavior. As the network becomes more homogeneous $(\Delta \rightarrow 0)$, more complex dynamic including aperiodic and multistability emerge from the macroscopic mean field.

\section{Author details}

${ }^{1}$ School of Physics, Astronomy,\& Computational Sciences, George Mason University, Fairfax, VA 22030, USA. ${ }^{2}$ The Krasnow Institute for Advanced Study, George Mason University, Fairfax, VA 22030, USA.

Published: 16 July 2012

\section{References}

1. Ariaratnam JT, Strogatz SH: Phase diagram for the Winfree model of coupled oscillators. Phys Rev Lett 2001, 86:4278-4281.

2. Ermentrout B: Type I membranes, phase resetting curves, and synchrony. Neural Comput 1996, 8(5):979-1001.

3. Ott E, Antonsen TM: Low Dimensional Behavior of Large Systems of Globally Coupled Oscillators. Chaos 2008, 18:037113.

4. Ott E, Antonsen TM: Long time evolution of phase oscillator system. Chaos 2009, 19:023117

doi:10.1186/1471-2202-13-S1-012

Cite this article as: Luke et al: A dynamical study of pulse-coupled oscillators in the brain. BMC Neuroscience 2012 13(Suppl 1):012.

\section{Submit your next manuscript to BioMed Central} and take full advantage of:

- Convenient online submission

- Thorough peer review

- No space constraints or color figure charges

- Immediate publication on acceptance

- Inclusion in PubMed, CAS, Scopus and Google Scholar

- Research which is freely available for redistribution

Submit your manuscript at www.biomedcentral.com/submit 